\title{
A Mathematical Model to Predict Frequency of Sand Nourishment in Straight Beaches
}

\author{
A.L. Dissanayake and K.P.P. Pathirana
}

\begin{abstract}
Beach nourishment is a viable engineering solution for shore protection by stabilizing beaches. However, beach nourishment may not be technically or economically feasible or justified for some sites, particularly those with high erosion rates. The frequency of re-nourishment is one of the important parameters that could be used to justify beach nourishment process for a given shoreline. Mathematical models could be effectively used for the above purpose. A mathematical model was developed for the simulation of shoreline changes due to both the longshore and crossshore sediment transport and there by, frequency of re-nourishment could be estimated. This model is an improved version to the typical' 'one-line model'. The model has been calibrated and verified against the field data collected from a beach nourishment project implemented in 2003 in a coastal stretch leading from Maha Oya to Lansigama in the west coast of Sri Lanka. The model results proved that the model is capable of simulating shoreline changes with a reasonable accuracy. Median grain size of beach sand and depth of closure are more sensitive to the model predictions compared to other input parameters. The applicability of the model is limited to straight coastlines without the presence of structures.
\end{abstract}

Keywords: Beach nourishment, sediment transport, beach erosion

\section{Introduction}

Beach erosion has become a major problem in many coastal regions in the world. As beaches become narrow and disappear, coastal communities and their properties become increasingly vulnerable to coastal hazards such as flooding and storm surges. It has threatened private properties, public facilities, infrastructure, and the economic and natural resources essential to the long-term viability of coastal communities around the world.

Severe erosion has become a hazard to thousands of families and small scale industries established along the beach and infrastructure along the Sri Lanka's coastal belt as well. Sri Lanka's, coastal zone serves as a focal point for economic development as $40 \%$ of the Gross Domestic Production with $70 \%$ total industrial output is coming from the coastal region. More than $80 \%$ of the tourismrelated infrastructure are located within this zone Samaranayake (2007). Moreover, marine ecosystems are also threatened by erosion. It is estimated that, out of the $1,562 \mathrm{~km}$ of Sri Lanka's coastline, approximately $500 \mathrm{~km}$ are subject to moderate to severe coastal erosion especially in the South, West and NorthWestern coasts (CCD, 1986). Therefore, it is important to take appropriate measures to protect coasts from erosion.

A number of engineering approaches are available to counteract the effects of erosion by stabilising beaches. Traditional approach to protect beaches from erosion has included 'hard structures' such as, seawalls, revetments, groins, and detached breakwaters. These structures can reduce wave attack and coastal flooding and thereby stabilise the beaches. However, these protective structures do not allow the natural movement of sediments in shorelines to takes place, causing severe erosion in adjacent beaches.

Beach nourishment is an alternative to shore protection structures that directly addresses the problem of sand budget deficit causing beach erosion as it is a process of adding sand from external sources. This results a wider beach that improves natural protection and provides additional recreational area. The

Eng. A.L. Dissmayake, B.Sc. Eng. (Hons.)(Peradeniya), MSc.Eng. (Peradeniya), Graduate Student, Department of Civil and Environmental. University of Clarkson, Potsdam, New York, USA.

Eng.(Prof.) K.P.P. Pathirana, B.Sc. Eng. (Hons.)(Peradeniya), M.Eng., Ph.D(KULeuven)., C.Eng, FIE(Sri Lanka),

MICE(London), Professor of Civil Engineering, Department of Civil Engincering, University of Peradeniya, Sri Lanka. 
presence of adequate sand reserves on beaches can allow for natural sediment movement to take place without any barriers. However, as a result of varying hydrodynamic condition in the near shore region in different seasons, the net long-term result would be the gradual loss of sand from beaches, demanding the renourishment process to continue in order to maintain stable beaches. However, the performance of beach nourishment projects can be substantially enhanced by the use of structures when they are appropriately designed and placed at suitable locations, thereby increasing the re-nourishment frequency. As the capital investments involved in these projects are generally high, it very important that a reliable estimation of sand renourishment frequency be known for economic justification of these projects. Mathematical models could be effectively used to compute frequency of sand re-nourishment for a given coastal stretch.

Most of the mathematical models available at present in simulating shoreline changes are based on the effect of longshore sediment transport only ('one-line model') and hence, the predictive capability of these models are limited where cross-shore sediment transport is significant. Few other models, namely, 'Nline models', reported in literature are capable of simulating shoreline changes due to both longshore sediment movement and also crossshore sediment transport. Detailed description of most of these models can be found in Hanson et al (1999), Dabees et al (2000). These models incorporate many empirical formulae to quantify sediment transport rates based on site specific details and hence, the general applicability of these models is rather limited.

The model presented in this paper is a $\mathrm{N}$-line model developed by incorporating both the longshore and cross-shore sediment movements to simulate shoreline changes with the objective of estimating re-nourishment frequency in beach nourishment projects.

\section{Model Development}

A basic assumption in one-line model is that the active beach profile moves in parallel to itself within a certain closure depth, beyond which the longshore sediment transport can be ignored and the profile does not change.
Applying the sediment continuity equation where the volumes of sand entering and leaving a particular cell are considered (Figure 1), the change of shoreline position can be computed using the following equation;

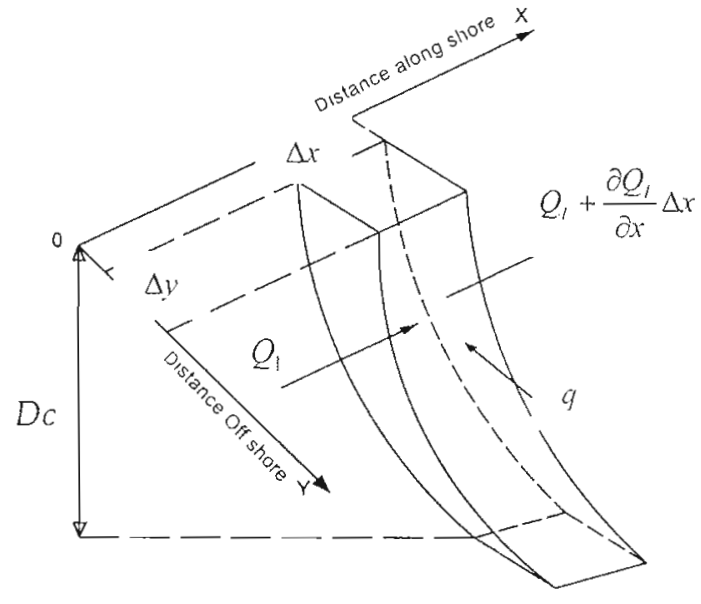

Figure 1 - Sketch of sediment balance

$d y= \pm \frac{q}{z}-\frac{d Q_{1}}{z \cdot d x} d t$

where, $Q_{l}$ is the volume rate of longshore transport, $q$ is the volume rate of sediments from an external source, $t$ is the time, $D_{C}$ is the closure water depth. One of the major shortcomings of this model is the omission of cross-shore sediment movement which is an important physical process in certain coastal stretches.

\subsection{N- Line Model}

By taking into account both the longshore and cross-shore transportation of sediments, one line model can be developed into $\mathrm{N}$-line model. In this model, a three dimensional coordinate system is considered, with $z$ axis placed in the downward direction from mean sea level in addition to $x$ and $y$ axes running along the coastline and offshore directions. Furthermore, each strip of the coastline of width $\Delta x$ used in the one-line model is divided into several cells with a height of $\Delta z$ along $z$ axis (Figure 2).

For a cell $(i, j)$ having a width of $\Delta x$ and height of $\Delta z$, incorporating both the cross-shore and longshore sediment transportation, the change in the shoreline position perpendicular to the shoreline is computed using Eq.(2) as follows,

$$
\begin{array}{r}
d y=\left[\left(Q_{l,(i, j)}-Q_{l,(i-1, j-i)}\right)-\left(Q_{c,(i-l . j-1)}-Q_{c,(i, j)}\right)\right]^{*} \\
\frac{d t}{\Delta z \cdot \Delta x} \pm \frac{q}{\Delta z} \ldots \ldots \ldots \ldots \ldots . .(2)
\end{array}
$$


where, $Q_{1}$ and $Q_{c}$ are the volume rates of longshore and cross-shore sediment transport, respectively. New shoreline position after time duration of $\Delta t, y_{t+\Delta t, 1}$, is computed as;

$y_{t+\Delta t, i}=y_{t, i}+d y$

where, $y_{t, i}$ - shoreline position at a time step $t$.

The finite difference form of Eq.(2) was solved using MATLAB software package.

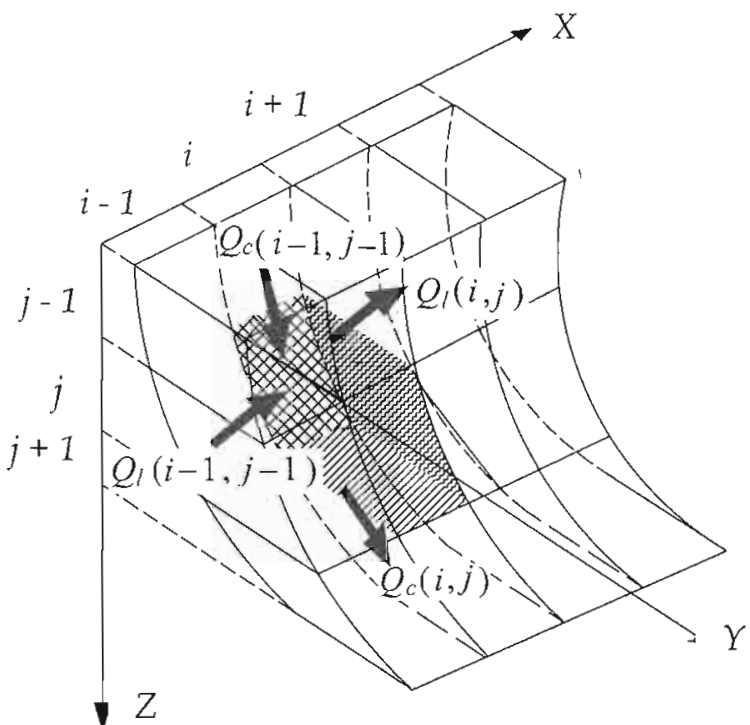

Figure 2 - Sediment entering and leaving a given element in $\mathrm{N}$ - Line model

a) Longshore Sediment Transport Rate $\left(Q_{l}\right)$

For the development of this model the volumetric rate of sediment transportation $Q_{l}$ was derived from the along-shore sediment transport formula based on "CERC" formula, (Shore Protection Manual, 1984) which is expressed as in the Eq.(4).

$Q_{l}=k \frac{\rho g^{\frac{1}{2}} H_{b}^{\frac{5}{2}}}{16\left(\rho_{s}-\rho\right) a \cdot \gamma_{b}^{0.5}} \sin \left(2 \alpha_{b}\right)$

where, $\rho_{s}$ and $\rho$ are density of sediments and density of water, respectively and $a$ is a correction factor for pore space of beach sand, approximately 0.6 for most beach deposits, $\alpha_{b}$ is the angle between breaking wave crests and shoreline, $H_{b}$ is wave height at breaking, $\gamma_{b}$ is breaker depth index which is taken as 0.78 , according to Komar (1976) neglecting beach slope and $k$ is a coefficient. b) Cross-Shore Sediment Transport Rate $\left(Q_{c}\right)$

Cross-shore sediment transport rate at different depths of the shore profile is the calculated according to Hanson et al (1999) as;

$Q_{c}=\xi \zeta . q_{0}$

where, $q_{0}$ - potential cross shore transport rate per unit length of the alongshore, $\xi$-Slope function and $\zeta$-Vertical distribution function which are described below.

Potential Cross-Shore Sediment Transport Rate $\left(q_{0}\right)$ :

This is calculated according to the Eq.(6), which is based on the assumption that bed is horizontal and unlimited availability of sand.

$q_{0}=K_{l} w\left[\frac{H_{b}^{3}}{d_{50}}\right]^{0.5}$

where, $K_{l}$-calibration parameter, $d_{50}$-median grain size and $w$-sediment fall speed which is computed as follows;.

$$
\begin{aligned}
& w=\frac{1}{18}\left(\gamma_{s}-1\right) \cdot g \cdot \frac{d_{50}{ }^{2}}{v} ; \text { for } d_{50}<0.0001 \\
& w=\frac{10 v}{d_{50}}\left\{1+\left(\frac{0.01\left(\gamma_{s}-1\right) \cdot g \cdot d_{50}{ }^{3}}{v^{2}}\right)^{0.5}-1\right\} ; \\
& \quad \text { for } 0.0001<d_{50}<0.001 \\
& w=1.1 .\left\{\left(\gamma_{s}-1\right) \cdot g \cdot d_{50}\right\}^{0.5} ; \text { for } d_{50}>0.001 \quad \ldots .(7)
\end{aligned}
$$

where, $\gamma_{s}$ - specific weight of sediments and $v$ Kinematic viscosity of water.

Slope Function, $\xi$ :

The slope function in the Eq.(5) is expressed according to Alkyon (1998) as follows;

$\xi=-\left[\frac{S}{S_{e}}-1\right]\left|\frac{S}{S_{e}}-1\right|$

where, $S$ and $S_{e}$ are the actual local inverted bed slope and the local inverted equilibrium slope respectively. In this equation if $S<S_{e}$, an offshore sediment transportation is obtained. 
Equilibrium Slope, $S_{e}$

The concept of equilibrium beach profile (EBP) has been used as a basis for assessing a characteristics shape to a beach. According to the definition of EBP given by Larson et al (1999), it is a profile shape that displays no net change in time, although sediment will be in motion. Using the EBP deduced by Bruun (1954) and Dean (1977), the average profile shape for a wide variety of beaches can in general be represented by,

$h=A y^{\frac{2}{3}}$

where, $h$ - water depth, $A$ - empirical scale parameter and $y$-horizontal distance from the shoreline. The scale parameter ' $A$ ' is calculated according to Moore (1982) which is reported to be dependent on median size of beach sand.

\section{Vertical Distribution Function, $\zeta$}

The distribution of cross-shore transport rate across a given profile is expressed by the vertical distribution function included in the Eq.(5). Hanson et al (1999) expresses the vertical distribution function as follows;

$$
\begin{aligned}
& \zeta=0.5 \cos \left(\frac{2 \pi h}{h^{*}}\right), \quad h \leq 0.75 h^{*} \\
& \zeta=0.5 e^{-4\left(\frac{h}{h^{-}}-0.75\right)}, h>0.75 h^{*}
\end{aligned}
$$

where, $h^{*}=2.28 h$ and $h^{*}$ - Instantaneous depth of closure and $h$ - local water depth.

\section{Data Collection}

\subsection{Study Area}

In order to calibrate and verify the proposed model, necessary data were collected from a beach nourishment project carried out in the west coast of Sri Lanka in 2003 which was initiated by the Coast Conservation Department (CCD) with the financial support from the Asian Development Bank. As a part of the coastline stabilization component of this major project, approximately $14 \mathrm{~km}$ long coastal stretch, from Maha Oya to Lansigama which is located between Negombo and Chilaw was nourished using offshore sand (Figure 3).

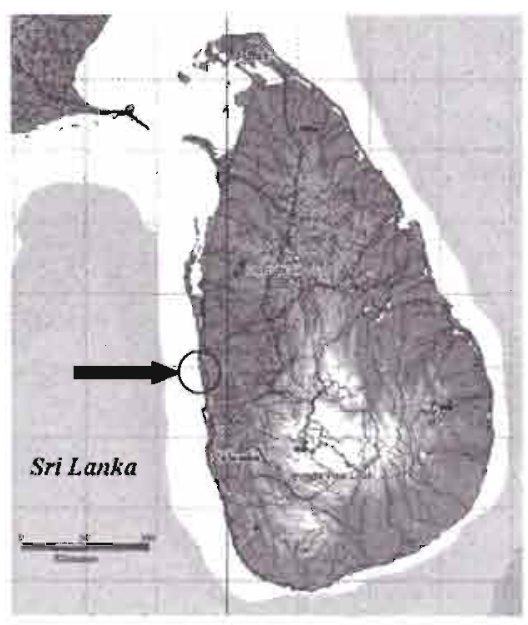

Figure 3 - Location of the Study Area

Under the aforesaid coast stabilization scheme, a series of groynes, detached breakwaters and revetments were also constructed in this coastal stretch in addition to about 2 million cubic meters of sand pumped from offshore creating a new beach of width varying approximately 40 to $50 \mathrm{~m}$. The field data gathered in carrying out the beach nourishment project was collected for the present study.

\subsection{Data Collection}

Out of $14 \mathrm{~km}$ long coastline, first $12 \mathrm{~km}$ stretch closer to Maha Oya in the southern end of the study area was incorporated with the coastal structures whereas, for the remaining $2 \mathrm{~km}$ long shoreline to the north near Lansigama, only the sand nourishment was done without any structures. As the proposed mathematical model is able to simulate shoreline changes in fairly straight beaches without any structures, $2 \mathrm{~km}$ long shoreline in the north of the area was selected for the present study.

The shore profiles of the selected coastal stretch were extracted from the data gathered for Coastal Resources Management Project [CRMP, 2007]. The repeated measurements of shore profiles were taken before and after the sand nourishment process in 2003 and also 3 years after the project, in 2006. The interval between the beach profiles is $50 \mathrm{~m}$ and these profiles extend to a depth of $6 \mathrm{~m}$ below mean sea level. 
The representative wave statistics for the study area during Southwest and Northeast monsoons which were derived based on the pre-established wave statistics in Chilaw and Colombo. The coastal sediments in this area are mainly of quartz sand and the median grain sizes were obtained from the dredging and reclamation records of the project. The median grain sizes of sand vary between $0.5 \mathrm{~mm}$ and $1.6 \mathrm{~mm}$.

\section{Model Calibration and Verification}

\subsection{Model Calibration}

The $2 \mathrm{~km}$ long coastal stretch selected for model application was divided into 42 strips having a width $(\Delta x)$ of $50 \mathrm{~m}$ and each strip was further divided into 10 cells with equal heights $(\Delta z=0.5 \mathrm{~m})$, up to water depth of $5 \mathrm{~m}$ from the mean sea level. It has been observed from the shore profiles collected in 2003 and 2006 that no significant changes were shown in these profiles beyond the $5 \mathrm{~m}$ water depth below mean sea level, and hence, the depth of closure in the model was taken as $5 \mathrm{~m}$.

Since only one set of field data was available for the present study to carry out both model calibration and verification, it was decided to use first 21 strips for model calibration while the remaining strips for model verification. It would have been much better if completely independent data set were available for model verification but failing which, the above approach was the only option available for us to carry out the present task. The coordinates of the coastal stretch used for model calibration are ranging from $94997.5 \mathrm{E}, 242100.98 \mathrm{~N}$ to $95192.6 \mathrm{E}, 241122.1 \mathrm{~N}$.

Deep water wave climates during Southwest and Northeast monsoon seasons were transformed to the nearshore region just outside the wave breaker zone. The wave heights and approach angles at breaking were computed using a simple wave breaking criteria. The beach profiles measured in 2003 after sand nourishment and in 2006 were used for model calibration. The parameter $K_{I}$ in Eq.(6) was used as the calibration parameter. Taking the shoreline position measured in 2003 as the initial shoreline, model simulations were performed to predict the shoreline position in 2006 such that the difference between the predicted and measured shoreline positions in
2006 was minimum. Figure 4 shows a comparison between the simulated and actual positions of the shoreline in 2006 during the calibration of the model. The percentage error between the actual and predicted shoreline positions varies between $12 \%$ and $31 \%$.

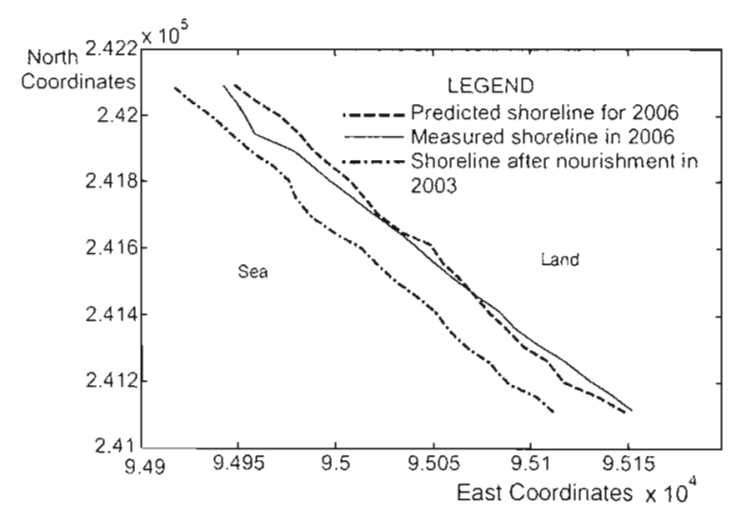

Figure 4 - Comparison between the simulated and measured shoreline positions in 2006 obtained during model calibration.

\subsection{Model Verification}

As mentioned in the previous section, the model was verified using the shoreline stretch with another 21 strips which was not used for model calibration and the coordinates of the coastal stretch used for model verification are ranging from $95202.4 \mathrm{E}, 241073.1 \mathrm{~N}$ to $95388.2 \mathrm{E}$, 240141.4 N. A comparison of the predicted and measured shoreline positions in 2006 is shown in Figure 5. It appears that the model predictions are quite reasonable. The percentage error between the measured and predicted shoreline positions obtained during model verification varies between $8 \%$ and $24 \%$.

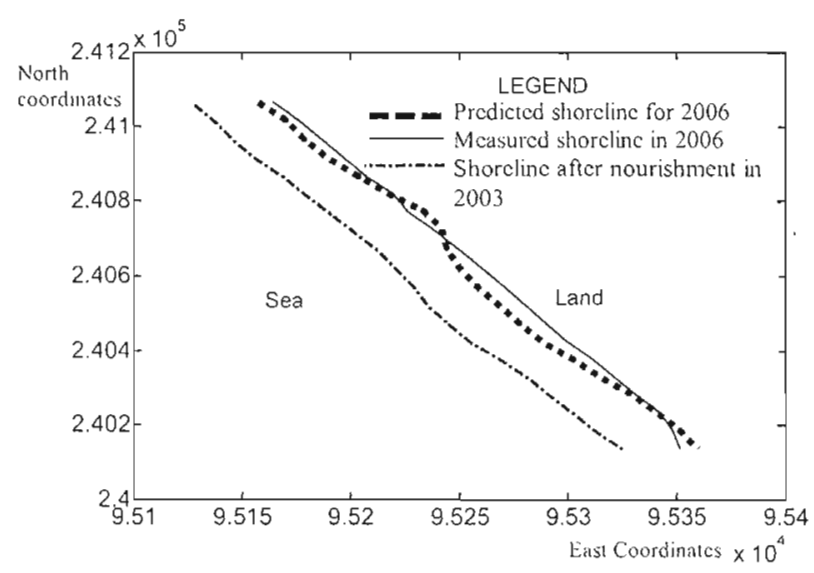

Figure 5 - Comparison between the simulated and measured shoreline positions in 2006 obtained during model verification. 


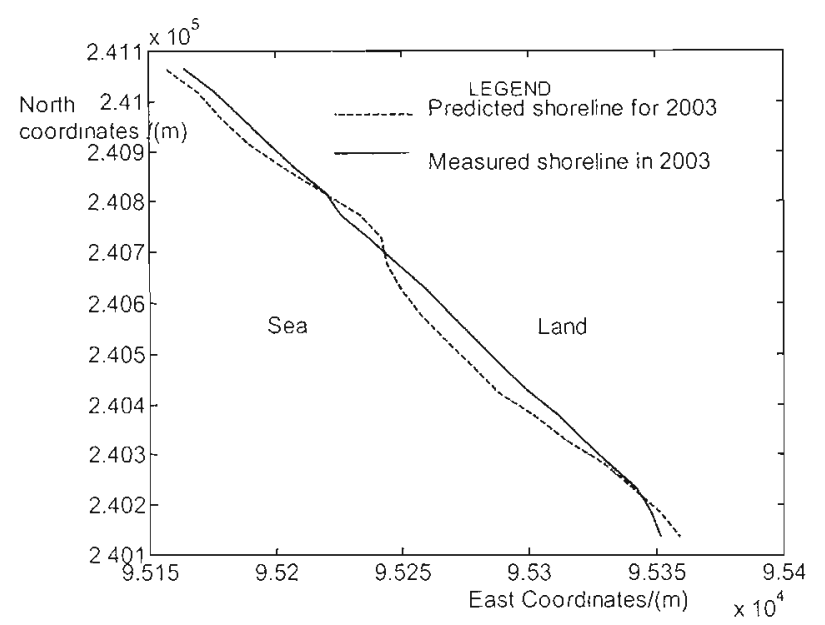

Figure 6 - Comparison of the measured shoreline position before sand nourishment in 2003 with the predicted shoreline after 4 years.

\subsection{Frequency of Beach Nourishment}

The proposed model was then applied to the same area to estimate the frequency of sand nourishment. This was done by using the shoreline position in 2003 after the sand nourishment as the initial profile and model simulations were carried out until the simulated shoreline was reasonably compares with the measured shoreline position in 2003 prior to sand nourishment. The frequency of sand nourishment predicted by the model was approximately 4 years. This duration appears to be reasonable with the value obtained from independent studies reported for the same coastal stretch. The comparison between the simulated and measured shoreline positions are shown in Figure 6.

Sensitivity analysis was also carried out for different model parameters and it shows that the model predictions are highly sensitive to the median size of beach sand compare with the other parameters. The depth of closure is the next parameter to influence models results and hence, these two parameters need to be accurately represented in the model for reliable model predictions.

\section{Summary and Conclusions}

A mathematical model was developed for the simulation of shoreline changes due to both the longshore and cross-shore sediment transport. This is an improved version of the conventional 'one-line model' which incorporates only the longshore sediment movement. In the proposed model, the shoreline is divided into a number of strips and each strip is again spilt into several cells in the vertical direction. Applying the sediment continuity equation to each cell where the volumes of sand entering and leaving a cell in longshore and cross-shore directions are considered, the change in shoreline position perpendicular to the coast is computed. This model can be used to estimate the frequency of re-nourishment in beach fill projects.

The model has been calibrated and verified against the field data collected from a beach nourishment project implemented in 2003 in a coastal stretch leading from Maha Oya to Lansigama in the west coast of Sri Lanka. The beach profiles measured at every $50 \mathrm{~m}$ interval, in the year 2003 before and after sand nourishment and again in 2006 were used for model calibration and verification. Deep water wave climates during the Southwest and Northeast monsoon seasons were transformed to the wave breaker zone and the resulting wave parameters were given to the model as input parameters. The model results appear to be more realistic indicating that the model is capable of simulating shoreline changes with a reasonable accuracy.

According to the model simulations, the frequency of re-nourishment of the selected coastal stretch was obtained as 4 years, which is found to be comparable with the values obtained from other studies carried out for the same beach. Sensitivity analysis carried out on the model parameters indicates that the median grain size of beach sand and depth of closure are more sensitive to the model predictions compare to other input parameters.

The applicability of the model is limited to straight coastlines without the presence of structures. The model could be further improved to make it applicable over shorelines with different configurations and also to include the coastal structures.

\section{Acknowledgments}

Authors wish to thank the Director and the staff of Coast Conservation Department for providing us with the necessary field data for model calibration and verification. 


\section{References}

1. Alkyon "Pilot Version of Pon Tos Model" Report A066/H3159, National Institute for Coastal and Marine Management/RWS-RIKZ, 4 Volumes, Enmeloord, The Netherlands, 1998.

2. Bruun, P., "Coast Erosion and the Development of beach profiles", Technical Memorandum No. 44, Beach Erosion Board, US Arny Corps of Engineers, 1954.

3. CERC Shore Protection Manual, US. Army Corps of Engineers, Coastal Engineering Research Center, 1984.

4. Coast Conservation Department (CCD), Sri Lanka Master Plan for Coastal Erosion Management. Volume I. CCD and the Danish International Development Agency. 142 pp. 1986.

5. Coastal Resource Management Project, CRMP, Coastal Stabilization Component, Design and Construction Supervision (ADB SRI 1716), CRMP_CSC D and S. Draft Detailed/Design Report No.1, Vol: Main Report, November 2001.

6. Dabees, M, Kamphius,J.W., N-Line efficient Modelling of $3 \mathrm{D}$ beach change, ICCE, Sydney, Australia, 2000.

7. Dean, R.G., "Equilibrium beach profiles: US Atlantic and Gulf coasts", Department of Civil Engineering, Ocean Engineering, Report No. 12, University of Delaware, Newark, DE, 1977.

8. Hanson Hans, Larson Magnus, Extension of "GENESIS" into the cross shore dimension from 1 - line to $n$ - line, COPEDEC V, pp. 312$323,1999$.

9. Komar, P. D., and Inman, D. L., "Longshore sand transport on beaches", Journal of Geophysical Research75 (30), pp. 5514-5527, 1976.

10. Komar, P.D., "Beach Process and Sedimentation", Prentice Hall Inc, Englewood Cliffs, New Jersey, pp.186-194, 1976.

11. Larson M, Nicholas C. Kraus, Randall A Wise, "Equilibrium beach profiles under breaking and non-breaking Waves", Coastal Enginecring, Elsevier, Vol. 36, 59-85, 1999.

12. Moore, B., "Beach Profile Evolution in Response to Changes in Water Level and Wave Height", M.S. Thesis, Department of Civil Engineering, University of Delaware, Newark, DE, 1982.
13. Samaranayake R.A.D.B, "Pre-and posttsunami coastal planning and land-use policies and issues in Sri Lanka", Coast Conservation Department, Sri Lanka, 2007, <http://www. rrcap.unep.org/reports/soe/srilanka_coastal. pdf $>$. 